\title{
Huge and Bilateral Lipomas of the Tongue: Case Report
}

\author{
Oussama Amraoui*, Sophia Nitassi, Razika Bencheikh, Anas Benbouzid, Abdelilah Oujilal, Leila Essakalli
}

Department of Otolaryngology, Head and Neck Surgery, Ibn Sina University Hospital, University Mohamed 5, Rabat, Morocco

DOI: $10.36347 /$ simcr.2021.v09i01.008

| Received: 06.09.2020 | Accepted: 15.09.2020 | Published: 14.01.2021

*Corresponding author: Amraoui Oussama

Abstract

Lipoma is the commonest tumor of human body, but the localization in the tongue is very rare especially since it is bilaterally. We report a very rare case of huge and bilateral lipomas of tongue for which complete tumor excision was done without recurrence after 1 year of follow up.

Keywords: lipoma, tongue, surgery.

Copyright $\odot 2021$ The Author(s): This is an open-access article distributed under the terms of the Creative Commons Attribution 4.0 International License (CC BY-NC 4.0) which permits unrestricted use, distribution, and reproduction in any medium for non-commercial use provided the original author and source are credited.

\section{INTRODUCTION}

Lipomas are common benign soft tissue masses consisting of adipocytes encapsulated by a layer of connetive fibrous tissue. However, their location in the oral cavity is rare with an incidence of $1-5 \%$ of all benign oral lesions [1]. Furthermore, very few cases with bilateral lipomas of the tongue have been reported in the literature.

\section{Case Report}

A 77 years old male patient presented at our oto rhino laryngology and head and neck surgery department with a huge and bilateral tumors on lateral borders of the tongue. It had been slowly growing for 4 years. The patient had difficulty with speech and mastication; he had also hypersialorrhea without pain or weight loss. Moreover he used to wake up from sleep frequently. Patient's and family history was not contributory. On clinical examination, we finded two yellowish and doughy lesions, with superficial blood vessels, localized on lateral borders of the tongue, extent of the tip and exceeding the lingual $\mathrm{V}$ [fig 1]. It was approximately $8 \times 3 \mathrm{~cm}$ to the right and $9 \times 2 \mathrm{~cm}$ to the left. Palpation finds a tumor that was soft and compressible and there was no palpable lymphadenopathy. Cervical CT scan showed 2 masses at the lateral edges of the tongue of regular contours and greasy density in spontaneous contrast between 95 and
110. The one on the left measures $85 \times 22 \times 15 \mathrm{~mm}$ and the one on the right measures $73 \times 35 \times 10$. Under general anesthesia, through a longitudinal incision on each tumor [fig 2], both tumors were excised [fig 3] and histopathologically analyzed. Macroscopically, the lesions appeared yellow and multinodular in shape and well encapsulated with a thin overlying mucosa [fig 4]. Their sizes were $8.5 \times 6 \times 2 \mathrm{~cm}$ and $9.3 \times 5 \times 2 \mathrm{~cm}$. Microscopically examination revealed that the lesion consisted of mature adipocytes with an empty cytoplasm pushing back the nuclei in the periphery. These adipocytes are arranged in lobules which are circumscribed by thin fibrous septa. The histopathological diagnosis was classical lipoma. The patient was followed up over 2 year and there was no recurrence of the tumor.

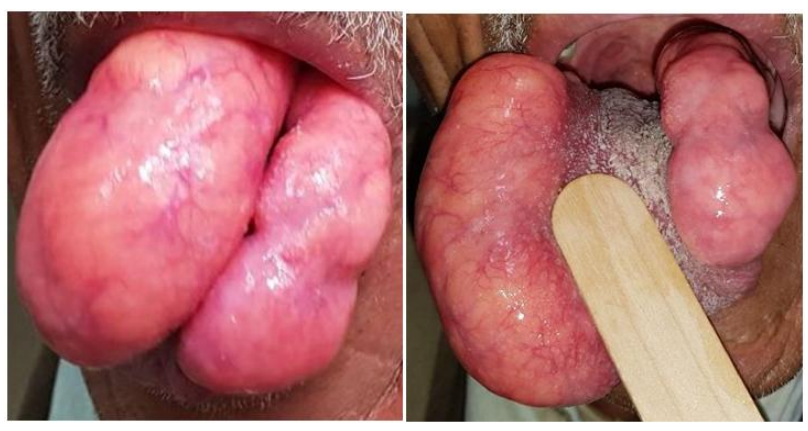

Fig-1 


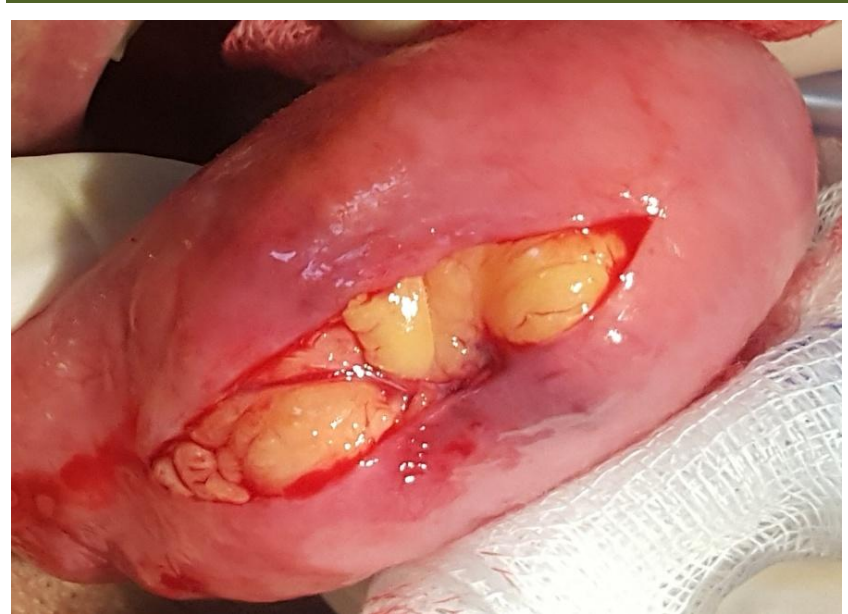

Fig-2

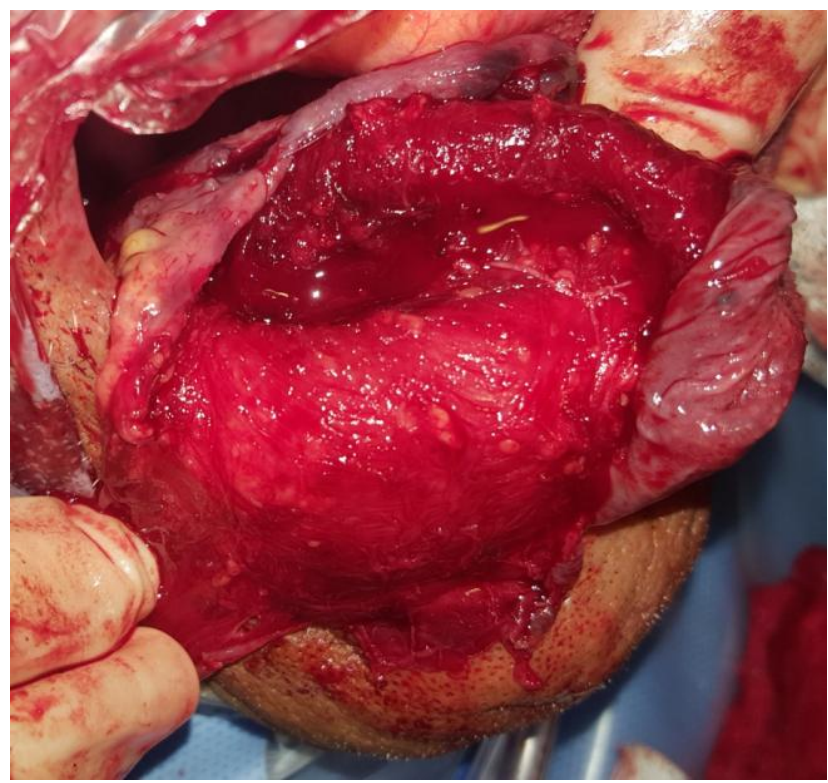

Fig-3

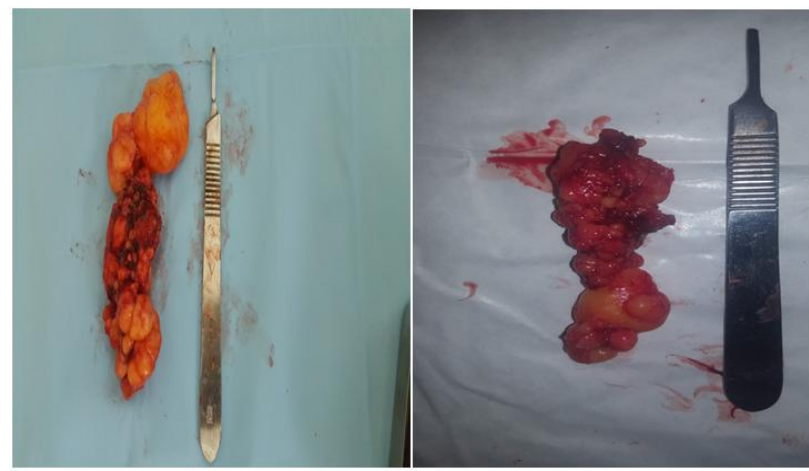

Fig-3

\section{DisCUSSION}

Lipomas are common tumors, but the oral cavity localization is rare, comprising no more than 1$5 \%$ of all the neoplasms [1] and lingual lipomas account for $0.3 \%$ of tongue neoplasms [2]. The first case of lingual lipoma was crediteted to Barling in 1858 [3]. Tongue lipomas have been seen at all ages but some studies reported that they appear frequently in adults
$>40$ years of age [4]. Fregnani and al. demonstrate an equal gender predilection [5]. It's described as being a gradually evolving tumor; it seems homogeneous with regular outlines and shows a yellowish hue, surmounted by a mucous membrane with superficial blood vessels [6]. The palpation finds a soft, mobile and painless tumor. The average diameter is $2.1 \mathrm{~cm}$, with a range of $0.5-10 \mathrm{~cm}[7,8]$. It can develop at the tip, root, lateral and ventral region of the tongue, but the latter is the most common location [4]. Generally it's asymptomatic until they grow to large sizes, then the patient can suffer from difficulty in mastication, swallowing, speech and respiration, tongue mobility and taste can be impaired. The mean duration for tongue lipoma resence has been reported as 3.2 years $[8,9]$.

On ultrasonography lipomas is hypo- echoic with echogenic lines or spots, while on CT scan it shows a high density from 83 to 143 Hounsfield units with well or poorly defined margins depending on the capsule [10].

Surgery is the key of treatment. Intramuscular or infiltrative lipomas are difficult to extirpate because they're often more deeply situated, not encapsulated, and have an infiltrative growth pattern, that's why this type has a high rate of recurrence[11]. So that it's advisable to do a wide surgical excision with a little cut off surrounding normal tissue while conserving surrounding structures $[5,12]$. Recurrence rate of as high as $62.5 \%$ has been recorded [13]. Our patient had well encapsulated lipomas without infiltrating other structures. Wide surgical excision had been done for both lipomas without damaging surrounding structures. The patient has been seen every month over 2 years and there was no recurrence.

Histologically, lipomas can be classified as classic lipomas or its variants, such as fibrolipomas, intramuscular lipomas, and spindle lipomas. The first 2 types accounted for approximately $80 \%$, followed by intramuscular lipomas and spindle cell lipomas [11]. Classical lipoma is composed of mature adipocytes embedded in a stroma of connective tissue; it's the most common type. Between 1909 and 2013 only 64 cases of tongue lipoma were reported in English literature and $44 \%$ of cases were classical lipomas [3]. In our case, the histopathological diagnosis was classical lipoma.

\section{CONClusion}

Bilateral lipomas are very rare and can be causes of macroglossia. At the beginning they are asymptomatic then after they grow in volume and cause a compressive symptomatology. Surgery is the key of treatment and must be done carefully to avoid recurrence. Histopathological exam shows the presence of mature adipocytes. 


\section{ACKNOWLEDGMENT}

We like to thank our Senior Professors of the department for her valuable guidance during treatment of this case

\section{REFERENCES}

1. Capodiferro S, Scully C, Maiorano E, Lo Muzio L, Favia G. Liposarcoma circumscriptum (lipomalike) of the tongue: Report of a case. Oral Dis. 2004;10:398-400.

2. Damghani MA, Safari M. Huge Tongue Lipoma: A Case Report. Iranian Journal of Otorhinolaryngology. 2015;27(79):165-169.

3. Baonerkar HA, Vora M, Sorathia R, Shinde S. The lipoma of tongue - A rare site for a tumor: Case report and review of the literature. Indian Journal of Dentistry. 2015;6(4):207-210.

4. Lu SL, Zheng JJ, Wu H, Li T, Dong G, Wang YL, Yang PS. Tongue lipoma in an older male: A case report and literature review of patients with tongue lipoma reported in China. Oncology letters. 2016 Jan 1;11(1):419-22.

5. Fregnani ER, Pires FR, Falzoni R, Lopes MA and Vargas PA: Lipomas of the oral cavity: Clinical findings, histological classification and proliferative activity of 46 cases. Int J Oral Maxillofac Surg. 32: 49-53, 2003.

6. Wu YH, Lin PY, Chang MH, Chiang CP. Lipoma of the tongue. Journal of the Formosan Medical Association $=$ Taiwan yi zhi. 2017 Dec;116(12):1006.
7. Juliasse LE, Nonaka CF, Pinto LP, de Almeida Freitas R, da Costa Miguel MC. Lipomas of the oral cavity: clinical and histopathologic study of 41 cases in a Brazilian population. European archives of oto-rhino-laryngology. 2010 Mar 1;267(3):45965.

8. Chandak S, Pandilwar PK, Chandak T, Mundhada R. Huge lipoma of tongue. Contemporary Clinical Dentistry. 2012;3(4):507-509.

9. Magadum D, Sanadi A, Agrawal JM and Agrawai MS: Classic tongue lipoma: A common tumour at a rare site. BMJ Case Rep. 30: 1-4, 2013.

10. Annibali S, Cristalli MP, Monaca GL, Giannone N, Testa NF, Russo LL, Muzio LL. Lipoma in the soft tissues of the floor of the mouth: A case report. The Open Otorhinolaryngology Journal. 2009 Jun $16 ; 3(1)$.

11. Naruse T, Yanamoto S, Yamada SI, Rokutanda S, Kawakita A, Takahashi H, Matsushita Y, Hayashida S, Imayama N, Morishita K, Yamashita K. Lipomas of the oral cavity: clinicopathological and immunohistochemical study of 24 cases and review of the literature. Indian Journal of Otolaryngology and Head \& Neck Surgery. 2015 Mar 1;67(1):67-73.

12. Furlong MA, Fanburg-Smith JC, Childers EL. Lipoma of the oral and maxillofacial region: Site and subclassification of 125 cases. Oral Surgery, Oral Medicine, Oral Pathology, Oral Radiology, and Endodontology. 2004 Oct 1;98(4):441-50.

13. Dattilo DJ, Ige JT, Nwana EJ. Intraoral lipoma of the tongue and submandibular space: report of a case. Journal of oral and maxillofacial surgery. 1996 Jul 1;54(7):915-7. 